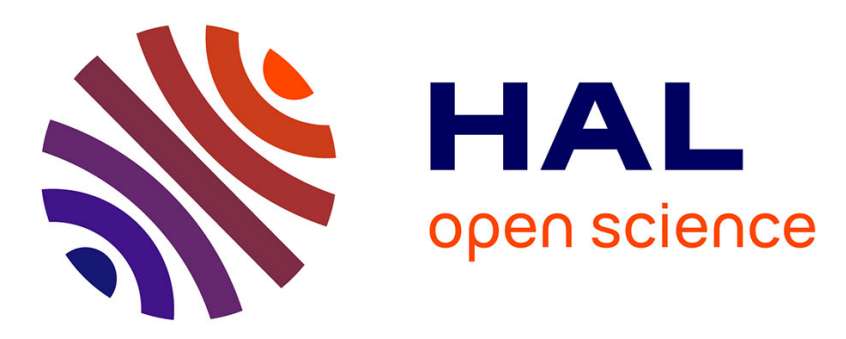

\title{
Construction of Enantioenriched 4,5,6,7-Tetrahydrofuro[2,3-b]pyridines through a Multicatalytic Sequence Merging Gold and Amine Catalysis
}

Manon Genet, Abdelilah Takfaoui, Jérôme Marrot, Christine Greck, Xavier Moreau

\section{To cite this version:}

Manon Genet, Abdelilah Takfaoui, Jérôme Marrot, Christine Greck, Xavier Moreau. Construction of Enantioenriched 4,5,6,7-Tetrahydrofuro[2,3-b]pyridines through a Multicatalytic Sequence Merging Gold and Amine Catalysis. Advanced Synthesis and Catalysis, In press, 10.1002/adsc.202100756 . hal-03319678

\section{HAL Id: hal-03319678 \\ https://hal.science/hal-03319678}

Submitted on 1 Sep 2021

HAL is a multi-disciplinary open access archive for the deposit and dissemination of scientific research documents, whether they are published or not. The documents may come from teaching and research institutions in France or abroad, or from public or private research centers.
L'archive ouverte pluridisciplinaire HAL, est destinée au dépôt et à la diffusion de documents scientifiques de niveau recherche, publiés ou non, émanant des établissements d'enseignement et de recherche français ou étrangers, des laboratoires publics ou privés. 


\title{
Construction of Enantioenriched 4,5,6,7-Tetrahydrofuro[2,3- b]pyridines through a Multicatalytic Sequence Merging Gold and Amine Catalysis
}

\author{
Manon Genet, ${ }^{\ddagger}$ Abdelilah Takfaoui,,${ }^{\ddagger}$ Jérôme Marrot, Christine Greck, Xavier Moreau* \\ Institut Lavoisier de Versailles (ILV), Univ. Versailles-St-Quentin-en-Yvelines, Univ Paris Saclay, UMR CNRS 8180, \\ 78035 Versailles Cedex, France
}

\begin{abstract}
A series of enantioenriched fused bicyclic piperidines were accessed by a cycloisomerization /cycloaddition strategy. Starting from ynamide derivatives and aldehydes, good yields and high levels of stereoselectivity were obtained through sequential relay catalysis. The concurrent use of a gold complex with a diphenylprolinol silyl ether was applied to a combination of diversely functionalized substrates.
\end{abstract}

Keywords: Aminocatalysis; Gold catalysis; Relay catalysis; Aza-Diels-Alder; Saturated heterocycles

The asymmetric catalytic construction of N-saturated heterocycles continues to attract considerable attention because of the prevalence of these structural motifs in natural products or biologically active compounds and because $\mathrm{sp}^{3}$-rich nitrogen scaffolds are among the most important structural components of pharmaceuticals. ${ }^{[1]}$ Aza-Diels-Alder reaction (ADAR) illustrates perfectly this finding. Over the past decades, a myriad of elegant stereoselective methods promoted by a chiral catalyst have been reported thus highlighted the effectiveness of this transformation for the synthesis of useful nitrogen heterocycles. ${ }^{[2]}$ Particularly in recent years, many research groups have exploited the ability of chiral organic molecules to activate diene and/or dienophile partners and allow normal or inverse electron-demand [4+2] cycloaddition to take place. ${ }^{[3]}$ Among the different activations made possible by these promoters, aminocatalytic HOMO-raising strategies have successfully demonstrated the propensity of chiral secondary amines to activate carbonyl compounds as electron-rich dienes or dienophiles to undergo such transformation. ${ }^{[4]}$ Illustrating the potential of such activation mode, Chen reported the first aminocatalytic asymmetric inverseelectron-demand Aza-Diels-Alder reaction of $\mathrm{N}$ - sulfonyl-1-aza-1,3-butadienes and aliphatic aldehydes. $^{[5-6]}$ The methodology has been further implemented in remote functionalization of $\alpha, \beta-$ unsaturated carbonyls with the concomitant use of cyclic 1-azadiene. ${ }^{[7]}$ Thus, preformed electron-poor heterodienes bearing cyclic sulfonamides, and sulfamidates, ${ }^{[8]}$ benzoxazoles and benzothiazoles, ${ }^{[8 \mathrm{a}]}$ benzothiazolimine ${ }^{[9]}$ or aurones-derived azadienes ${ }^{[10]}$ have been engaged in the organocatalyzed cycloaddition reaction giving rise to diverse nitrogencontaining polycyclic architectures (scheme 1). Despite great advances, new methodologies emphasizing the generation of structural diversity and complexity have yet to be explored. In this context, the combination of different catalysts to achieve synthetic efficiency and stereoselectivity inaccessible by a single catalyst is a promising strategy to address this challenge. ${ }^{[11]}$

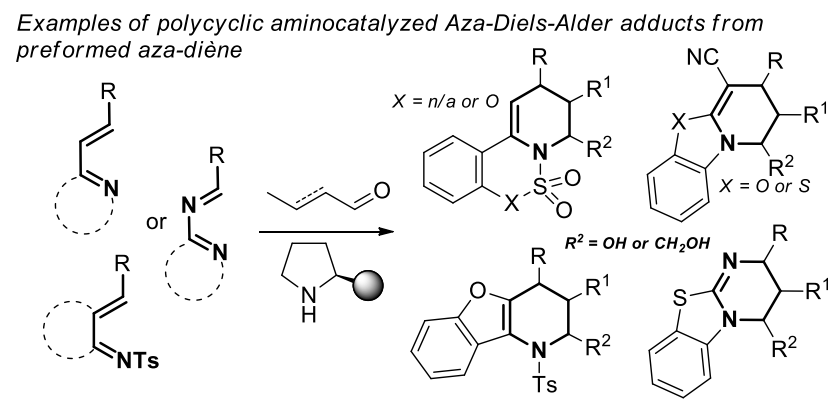

This work : Relay catalytic strategy toward furan-fused-piperidine motifs

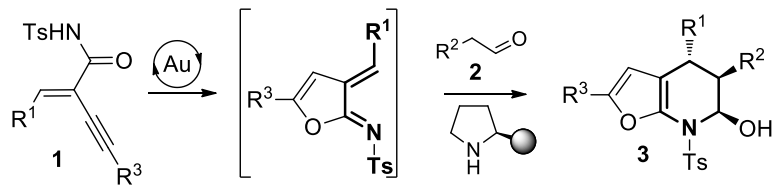

Scheme 1. Aminocatalytic HOMO-raising strategies toward polycyclic piperidines 
In this area, multicatalytic processes that merge the complementary activation offered by a metal and an organocatalyst have allowed the construction of enantioenriched complex structures from simple starting materials. In particular, cooperative (synergistic) or relay catalysis that employ the combination of an aminocatalyst with palladium, copper, iridium, ruthenium, platinium or gold complexe have been used to synthesize functionalized enantioenriched cyclic motifs. ${ }^{[12]}$ We described herein a relay catalytic strategy using the complementary activations of gold catalysis and aminocatalysis for the stereoselective formation of enantioenriched furanfused piperidine motifs. Very recent reports have shown that gold-catalyzed cycloisomerization of ynamides 1 could afford competent four-atom reaction partners that could be engaged in catalytic cyclization reactions. ${ }^{[13]}$ We surmised that the transient azadiene formed during this catalytic event could be engaged in an aminocatalytic cycloaddition leading to the targeted skeletons. But we had to be mindful that a careful optimization of the reaction conditions ensuring the compatibility of the two catalytic steps was the key to the success of this tactic. We began our studies by investigating the gold and chiral amine sequential relay catalysis of ynamide $\mathbf{1 a}$ and pentanal $\mathbf{2 a}$ (Table 1). Cycloisomerization reaction of $\mathbf{1 a}$ under gold(I) catalysis $\quad\left(\mathrm{Ph}_{3} \mathrm{PAuCl} / \mathrm{AgPF}_{6}, \quad 10 \mathrm{~mol} \%\right)$ in dichloroethane (DCE) at room for $1 \mathrm{~h}$ led to the formation of electron-poor azadiene. Successive additions of the diarylprolinol silyl ether $\mathbf{I a}^{[14]}$ with an equal amount of benzoic acid $(20 \mathrm{~mol} \%)$ and pentanal 2a enable the ADAR to proceed. In this case, the expected bicyclic compound 3a was obtained in $25 \%$ yield and $80 \%$ ee (entry 1). The influence of the aminocatalyst structure on the reaction was first investigated by using the catalyst Ib possessing a bulkier silyl group (e.g., TBS) and the 3,5- $\left(\mathrm{CF}_{3}\right)_{2} \mathrm{C}_{6} \mathrm{H}_{3}$ derived catalyst Ic (entries 2 and 3 ). Both catalysts Ib and Ic resulted in a decrease of yields and enantioselectivities. We then examined the influence of the solvent on the ADAR by exploiting the concept of ,pot-economy“ disclosed by Clarke ${ }^{[15]}$ and developed by Hayashi. ${ }^{[16]}$ This strategy consists in an "uninterrupted sequence of reactions" where only the removal of volatiles from the reaction vessel by distillation is allowed. Following this principle, the conditions of the cycloisomerization step remained identical and DCE was evaporated after $1 \mathrm{~h}$ and replace by $\mathrm{PhMe}$. Cat Ia, $\mathrm{PhCO}_{2} \mathrm{H}$, pentanal $\mathbf{2 a}$ were then added and the reaction mixture was stirred 24h (entry 4). In this case better yield (40\%) and enantioselectivity (98\%) were observed. As pointed out by Chen, ${ }^{[5]} \mathrm{H}_{2} \mathrm{O}$ plays a pivotal role in this cycloaddition reaction and facilitate the catalytic turnover. Indeed, addition of different amount of water in the sequence (entries 5-8) resulted a significant increase of yield (best conditions: $\mathrm{V}\left(\mathrm{H}_{2} \mathrm{O}\right)=0.025 \mathrm{~mL}$, $74 \%$ yield, entry 8) affording 3a with an excellent enantioselectivity (99\% ee).
Table 1. Optimization of the reaction conditions.

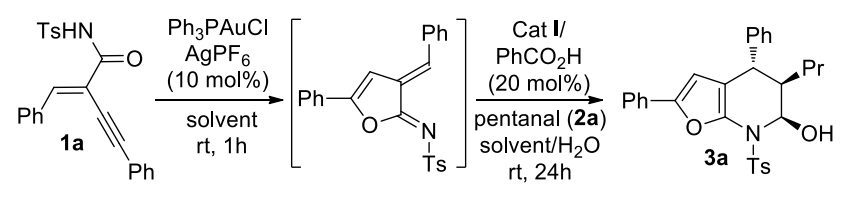

\begin{tabular}{|c|c|c|c|c|c|}
\hline entry & cat & solvent & $\begin{array}{l}\mathrm{H}_{2} \mathrm{O} \\
(\mathrm{mL})\end{array}$ & $\begin{array}{l}\text { yield } \\
(\%)^{b)}\end{array}$ & $\begin{array}{l}\text { ee } \\
(\%)^{c)}\end{array}$ \\
\hline 1 & Ia & DCE & - & 25 & 80 \\
\hline 2 & $\mathrm{Ib}$ & $\mathrm{DCE}$ & - & 10 & 50 \\
\hline 3 & Ic & DCE & - & 8 & n.d. \\
\hline $4^{\text {d) }}$ & Ia & DCE then PhMe & - & 41 & 98 \\
\hline $5^{\text {d) }}$ & Ia & DCE then PhMe & 0.1 & 45 & 99 \\
\hline $6^{\mathrm{d})}$ & Ia & DCE then PhMe & 0.2 & 35 & 99 \\
\hline $7^{\mathrm{d})}$ & Ia & DCE then $\mathrm{PhMe}$ & 0.05 & 63 & 99 \\
\hline $8^{d)}$ & Ia & DCE then PhMe & 0.025 & 74 & 99 \\
\hline 9 & Ia & $\mathrm{PhMe}$ & 0.025 & 68 & 99 \\
\hline $10^{\mathrm{e})}$ & Ia & DCE:PhMe $(1: 1)$ & 0.025 & 52 & 98 \\
\hline $12^{\mathrm{f})}$ & Ia & DCE:PhMe $(1: 4)$ & 0.025 & 63 & 99 \\
\hline
\end{tabular}

a) Reactions were performed with $\mathbf{1 a}(0.1 \mathrm{mmol})$, $\mathrm{Ph}_{3} \mathrm{PAuCl} / \mathrm{AgPF}_{6}\left(10 \mathrm{~mol}^{\%}\right)$ in solvent $(1 \mathrm{~mL})$ at $\mathrm{rt}$ for $1 \mathrm{~h}$ then $\mathrm{Cat} \mathbf{I} / \mathrm{PhCO}_{2} \mathrm{H}(20 \mathrm{~mol} \%)$, pentanal $(0.15$ mmol) and $\mathrm{H}_{2} \mathrm{O}$ were added. b) Isolated yields. $\left.{ }^{c}\right)$ Determined by HPLC on a chiral stationary phase. d) DCE was evaporated after the $1^{\text {st }}$ catalytic step and replace by PhMe $\left.(1 \mathrm{~mL}) .{ }^{\text {e) }} \mathrm{DCE} / \mathrm{PhMe}(1 \mathrm{~mL} / 1 \mathrm{~mL}) .{ }^{\mathrm{f}}\right)$ $\mathrm{DCE} / \mathrm{PhMe}(0.25 \mathrm{~mL} / 1 \mathrm{~mL})$.

We were finally interested in setting up compatible solvent conditions for the whole multicatalytic process (entries 9-11). When PhMe (entry 9) or a mixture DCE:PhMe (1:4) (entry 11) was used as solvent from the outset of the transformation, only a slight decrease in term of yield was observed (68 and 63\% respectively) but the high level of enantioselectivity was maintained (99\% ee). Finally, due to solubility problem encountered during the evaluation of the scope, the optimal condition to synthetize compounds 3 were selected as follow: ynamide 1 (0.1 mmol), $\mathrm{Ph}_{3} \mathrm{PAuCl} / \mathrm{AgPF}_{6}(10 \mathrm{~mol} \%)$ in a mixture $\mathrm{DCE} / \mathrm{PhMe}$ $(0.25 \mathrm{~mL} / 0.5 \mathrm{~mL})$ at $\mathrm{rt}$ for $1 \mathrm{~h}$ then a solution of cat. $\mathbf{I a} / \mathrm{PhCO}_{2} \mathrm{H}(20 \mathrm{~mol} \%)$ in $\mathrm{PhMe}(0.5 \mathrm{~mL})$, pentanal $(0.15 \mathrm{mmol})$ and $\mathrm{H}_{2} \mathrm{O}(25 \mu \mathrm{L})$ were added and the reaction mixture was stirred at room temperature for 24h. Having established the best conditions, the scope of the transformation regarding to the substituants $\left(\mathrm{R}^{2}\right.$ group) bore by ynamide 1 was explored (Table 2 ). We initially focused on the reactivity of $\alpha, \beta$-unsaturated ynamide 1b-1g decorated with a substituted aromatic ring on the benzylidene moiety. In all cases, bicyclic scaffolds 3 were obtained with a high level of diastereoselectivity $(>95 \%$ de). Regardless of the position (ortho, meta, para-position), the introduction 
Table 2. Substrate scope of the amides $\mathbf{1}^{[\mathrm{a}, \mathrm{b}]}$
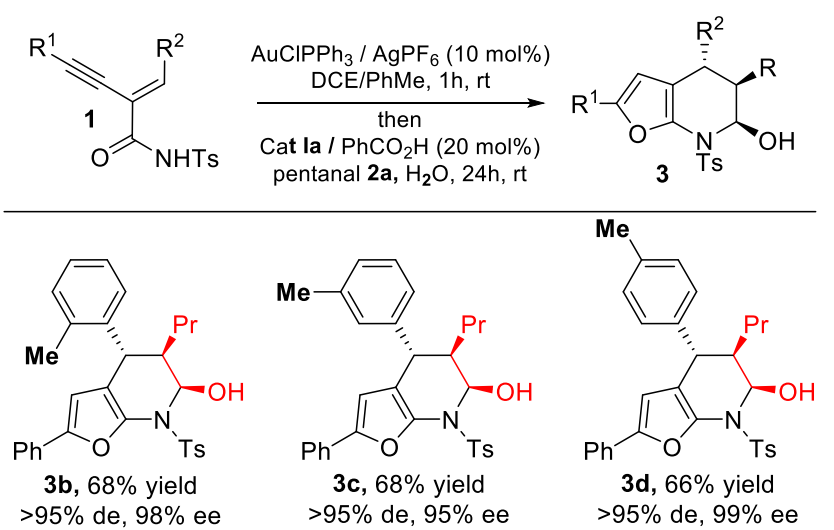

$3 d, 66 \%$ yield

$>95 \%$ de, $98 \%$ ee
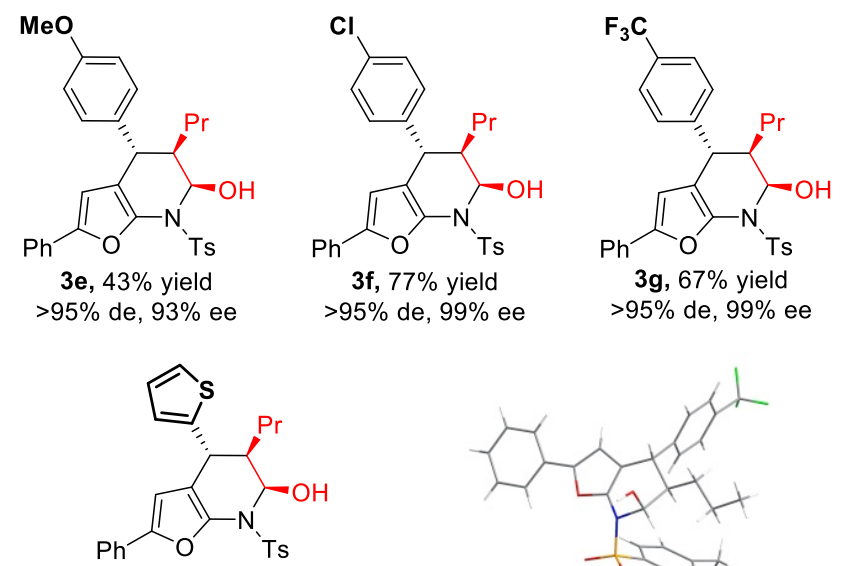

$3 \mathrm{~h}, 53 \%$ yield

$>95 \%$ de, $94 \%$ ee
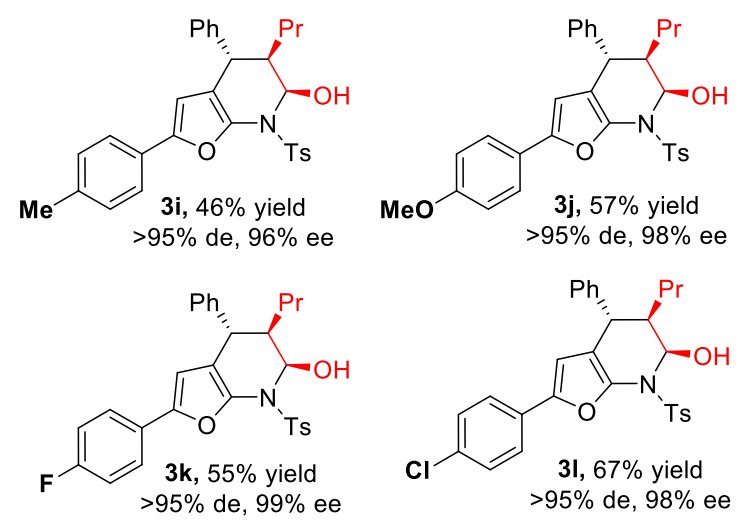

a) Reactions were performed with $\mathbf{1}(0.1 \mathrm{mmol})$, $\mathrm{Ph}_{3} \mathrm{PAuCl} / \mathrm{AgPF}_{6}(10 \mathrm{~mol} \%)$ in a mixture DCE/PhMe $(0.25$ $\mathrm{mL} / 0.5 \mathrm{~mL})$ at $\mathrm{rt}$ for $1 \mathrm{~h}$ then cat $\mathbf{I a} / \mathrm{PhCO}_{2} \mathrm{H}(20 \mathrm{~mol} \%)$, pentanal $(0.15 \mathrm{mmol}), \mathrm{H}_{2} \mathrm{O}(25 \mu \mathrm{L})$ and $\mathrm{PhMe}(0.5 \mathrm{~mL})$ were added. b) Yield refers to isolated yields after purification, diastereomeric excesses (de) were determined by ${ }^{1} \mathrm{H}$ NMR analysis of the crude and enantiomeric excesses (ee) were determined by HPLC on a chiral stationary phase.

of a methyl group did not influence the reaction outcome and bicyclic compounds $\mathbf{3 b} \mathbf{b}-\mathbf{3 d}$ were isolated with similar levels of yields and enantioselection as $\mathbf{3 a}$.
A decrease of yield and enantiomeric excess was observed on reacting $1 \mathbf{e}$

Table 3. Substrate scope of the aldehydes $2^{[a, b]}$
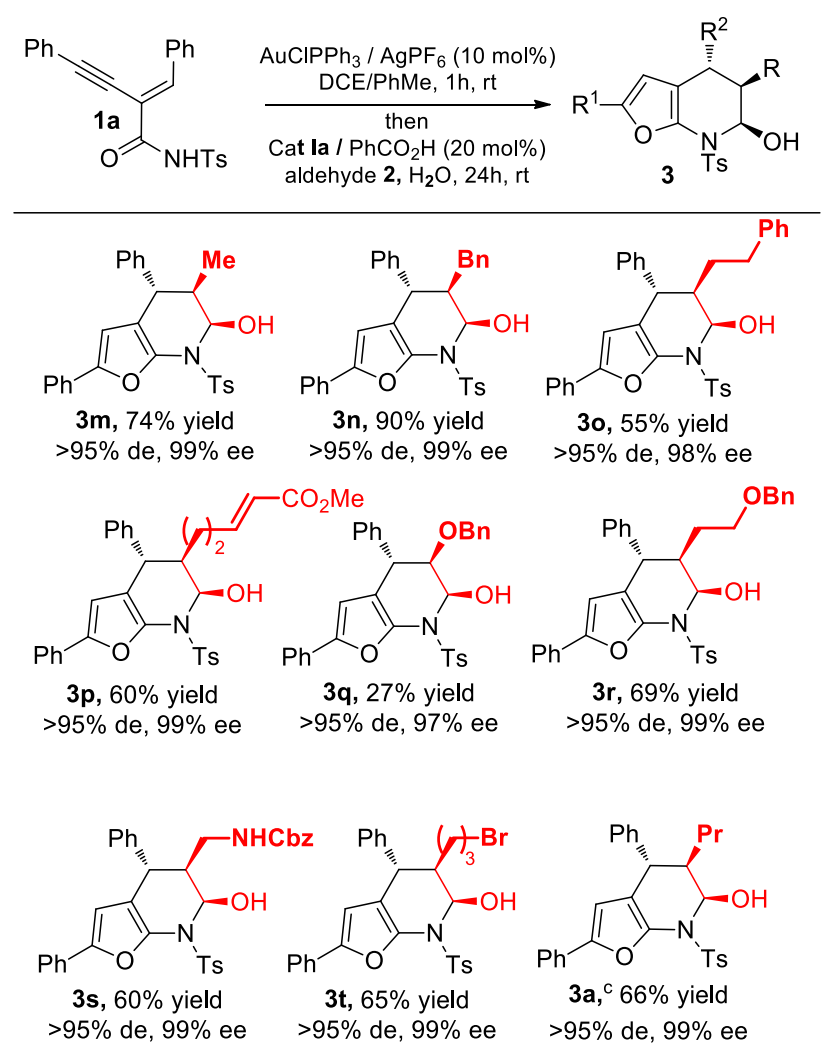

a) Reactions were performed with 1a $(0.1 \mathrm{mmol})$, $\mathrm{Ph}_{3} \mathrm{PAuCl} / \mathrm{AgPF}_{6}(10 \mathrm{~mol} \%)$ in a mixture DCE/PhMe (0.25 $\mathrm{mL} / 0.5 \mathrm{~mL})$ at $\mathrm{rt}$ for $1 \mathrm{~h}$ then cat $\mathbf{I a} / \mathrm{PhCO}_{2} \mathrm{H}(20 \mathrm{~mol} \%)$, aldehyde $2(0.15 \mathrm{mmol}), \mathrm{H}_{2} \mathrm{O}(25 \mu \mathrm{L})$ and $\mathrm{PhMe}(0.5 \mathrm{~mL})$ were added. b) Yield refers to isolated yields after purification, diastereomeric excesses (de) were determined by ${ }^{1} \mathrm{H}$ NMR analysis of the crude and enantiomeric excesses (ee) were determined by HPLC on a chiral stationary phase. c) reaction performed on $1 \mathrm{mmol}$ scale.

bearing a para-methoxy substituent with 2a In this case, 3e was obtained in $43 \%$ yield and $93 \%$ ee. Ynamides $\mathbf{1 f}$ and $\mathbf{1 g}$ bearing respectively a chlorine atom or a trifluoromethyl group at the para-position of the aromatic ring were also amenable to the cycloisomerization/ADAR sequence by providing compounds $\mathbf{3 f}$ or $\mathbf{3 g}$ in good yields and $99 \%$ ee. The structure and the relative configuration of $\mathbf{3 g}$ was unambiguously confirmed by single-crystal X-ray crystallography. ${ }^{[17]}$ The thiophene-derived-amide $\mathbf{1 h}$ was found to undergo a clean reaction to provide product $3 \mathrm{~h}$ with $53 \%$ yield and $94 \%$ ee. Unfortunately, no reaction took place when ynamide $\mathbf{1}$ bearing a strong electron withdrawing group $\left(\mathrm{R}^{2}=4-\mathrm{NO}_{2}-\mathrm{C}_{6} \mathrm{H}_{4}\right)$ or 1-naphthyl substituent was engaged in the sequence. Variations to the alkyne moiety ( $\mathrm{R}^{1}$ group) were next investigated. Aromatic substituents decorated with either a methyl, a methoxy-group or halogen atoms (F, $\mathrm{Cl}$ ) at the para-position are well tolerated, giving rise 
to the target products $\mathbf{3 i}-\mathbf{3 l}$ in yields ranging from $46 \%$ to $68 \%$ and excellent enantiomeric excesses $(>96 \%$ ee).
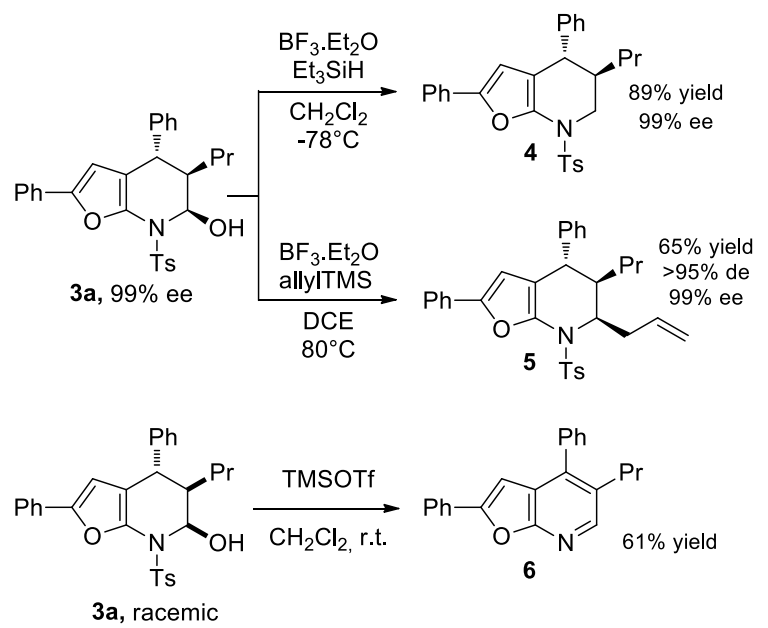

Scheme 2. Synthetic transformations

We then found that a variety of substituted aldehydes 2 are also amenable to the transformation with ynamide 1 a provided functionalized fused furans $\mathbf{3}$ in moderate to excellent yields and a high level of stereochemical induction was observed in each case $(>95 \%$ de, $>97 \%$ ee, table 3$)$. Not surprisingly, aliphatic aldehydes such as propanal, 3phenylpropanal or 4-phenylbutanal were well tolerated leading respectively to $\mathbf{3 m}, \mathbf{3 n}$ and $\mathbf{3 o}$ in good yields. More interestingly, functionalized aldehydes can also efficiently participate in this reaction. Bicyclic skeleton 3p bearing an alkyl chain decorated with and $\alpha, \beta$-unsaturated ester was formed in $60 \%$ yield. The reaction of $O$-protected $\alpha$ - or $\beta$-hydroxy aldehydes afforded bicyclic skeletons $\mathbf{3 q}$ and $\mathbf{3 r}$ in $27 \%$ and $69 \%$ yield. Similar result was obtained for compound 3s starting from $N$-protected $\beta$-amino aldehyde. A bromide-substituted chain was also a suitable substrate for this sequence and provided $\mathbf{3 t}$ in $65 \%$ yield. Finally, we demonstrate that the sequential relay catalysis of ynamide $\mathbf{1 a}$ and pentanal $\mathbf{2 a}$ still proceeded smoothly when performed on $1 \mathrm{mmol}$ scale. To further increase the functional-group diversity of our compounds, transformations of compound $\mathbf{3}$ into chiral piperidine motifs $\mathbf{4}$ and $\mathbf{5}$ were carried out. Compound $\mathbf{3 a}$ was stirred in the presence of $\mathrm{BF}_{3} . \mathrm{Et}_{2} \mathrm{O}$ and triethylsilane to yield 4 in $89 \%$ yield. Moving from a silicon-based reducing agent to trimethylallylsilane allowed the formation of more substituted piperidine ring $\mathbf{5}$ bearing three continuous stereocentres. Finally, the construction of biologically valuable furo[3,2b]pyridines ${ }^{[18]}$ from 3a was considered. A racemic mixture of $\mathbf{3 a}$ was engaged in an oxidative transformation in the presence of trimethylsilyl trifluoromethanesulfonate ( 1 equiv) to afford furo[3,2b]pyridine 6 in $61 \%$ yield.
In summary, we have developed a sequential relay catalytic transformation leading to enantioenriched functionalized bicyclic piperidines 3. A combination of $\mathrm{Ph}_{3} \mathrm{PAuCl} / \mathrm{AgPF}_{6}$ with OTMS-prolinol Ia catalyst turned out to be the best catalytic system to trigger the gold-catalyzed cycloisomerization / aminocatalytic cycloaddition sequence. Good yields and high levels of stereoselectivity were observed for a range of ynamides and aldehydes involved in the transformation.

\section{Experimental Section}

General procedure for the synthesis bicyclic piperidines 3 :

In a dried and nitrogen filled Schlenk flask, a mixture of $\mathrm{PPh}_{3} \mathrm{AuCl}$ (5.0 mg, $\left.0.01 \mathrm{mmol}, 10 \mathrm{~mol} \%\right), \mathrm{AgPF}_{6}(2.5 \mathrm{mg}$, $0.01 \mathrm{mmol}, 10 \mathrm{~mol} \%)$ in DCE $(0.25 \mathrm{~mL})$ was stirred at room temperature under nitrogen for $30 \mathrm{~min}$ to generate the gold catalyst. Ynamide $1(0.1 \mathrm{mmol})$ and toluene $(0.5 \mathrm{~mL})$ were added to the above catalyst solution under nitrogen. The resulting mixture was stirred for $1 \mathrm{~h}$. A solution of organocatalyst Ia $(6.5 \mathrm{mg}, 0.02 \mathrm{mmol}, 20 \mathrm{~mol} \%)$ in toluene $(0.5 \mathrm{~mL})$, benzoic acid $(2.1 \mathrm{mg}, 0.02 \mathrm{mmol}, 20 \mathrm{~mol} \%)$, aldehyde $2(0.15 \mathrm{mmol})$ and $\mathrm{H}_{2} \mathrm{O}(25 \mu \mathrm{L})$ were added. The resulting mixture was stirred $24 \mathrm{~h}$ at room temperature and concentrated under reduced pressure to afford the crude product. Preparative TLC purification (pentane/EtOAc) afforded the desired product 3 .

\section{Acknowledgements}

This work was supported by the French Ministère de l'Enseignement Supérieur et de la Recherche (M. G.) and the Agence Nationale de la Recherche (ArDCo proposal, number ANR-17-CE07-0050-03 (A. T.). We also thank the Université de Versailles-Saint-Quentin-en-Yvelines and the Centre National de la Recherche Scientifique (CNRS) for their financial support.

\section{References}

[1] a) D. G. Brown, J. Boström J. Med. Chem. 2016, 59, 4443-4458; b) M. S. Butler, A. A. Robertson, M. A. Cooper Nat. Prod. Rep. 2014, 31, 1612-1661; c) E. Vitaku, D. T. Smith, J. T. Njardarson J. Med. Chem. 2014, 57, 10257-10274; d) F. Lovering MedChemComm, 2013, 4, 515-519; e) F. Lovering, J. Bikker, C. J. Humblet J. Med. Chem. 2009, 52, 6752-6756.

[2] a) J. Merad, C. Lalli, G. Bernandat, J. Maury, G. Masson, Chem. Eur. J. 2018, 24, 3925-3943; b) M.-H. Cao, N. J. Green, S.-Z. Xu Org. Biomol. Chem. 2017, 15, 31053129; c) V. Eschenbrenner-Lux, K. Kumar, H. Waldmann Angew. Chem. Int. Ed. 2014, 53, 1114611157.

[3] a) M. G. Vinogradov, O. V. Turova, S. G. Zlotin $A d v$. Synth. Catal. 2021, 363, 1466-1526; b) M. S. Xie, L. L. Lin, X. M. Feng Chem. Rec. 2017, 17, 1184-1202; c) G. Blond, M. Gulea, V. Mamane Curr. Org. Chem. 2016 , 20, 2161-2210; d) M. Fochi, L. Caruana, L. Bernardi Synthesis 2014, 46, 135-157; e) G. Masson, C. Lalli, M. Benohoud, G. Dagousset Chem. Soc. Rev. 2013, 42, 902- 
923; f) J. Xianxing, R. Wang Chem. Rev. 2013, 113, 5515-5546.

[4] a) L. Klier, F. Tur, P. H. Poulsen, K. A. Jørgensen Chem. Soc. Rev. 2017, 46, 1080-1102; b) J. L. Vicario Synlett 2016, 27, 1006-1021; c) H. B. Hepburn, L. Dell'Amico, P. Melchiorre Chem. Rec. 2016, 16, 1787-1806; d) H. Jiang, L. Albrecht, K. A. Jørgensen Chem. Sci. 2013, 4, 2287-2300; e) I. D. Jurberg, I. Chatterjee, R. Tannert, P. Melchiorre Chem. Commun. 2013, 49, 4869-4883.

[5] a) B. Han, J.-L. Li, C. Ma, S.-J. Zhang, Y.-C. Chen Angew. Chem. Int. Ed. 2008, 47, 9971-9974; b) B. Han, J.-L. Li, C. Ma, S.-J. Zhang, Y.-C. Chen Angew. Chem. 2008, 120, 10119-10122.

[6] For selected examples see: a) J.-Y. Li, Z.-L. Li, W.-W. Zhao, Y.-K. Liu, Z.-P. Tong, R. Tan, Org. Biomol. Chem. 2016, 14, 2444-2453 S.-L. Zhou, J.-L. Li, L. Dong, Y.C. Chen Org. Lett. 2011, 13, 5874-5877; b) J.-L. Li, S.L. Zhou, B. Han, L. Wu, Y.-C. Chen Chem. Commun. 2010, 46, 2665-2667; Z.-Q. He, B. Han, R. Li, L. Wu, Y.-C. Chen Org. Biomol. Chem. 2010, 8, 755-757. B. Han, Z.-Q. He, J.-L. Li, R. Li, K. Jiang, T.-Y. Liu, Y.-C. Chen Angew. Chem. Int. Ed. 2009, 48, 5474- 5477.

[7] A. Skrzyńska, S. Frankowski, L. Albrecht Asian J. Org. Chem. 2020, 9, 1688-1700.

[8] a) Z. Zhou, Z.-X. Wang, Q. Ouyang, W. Xiao, W. Du, Y. C. Chen, Chem. Eur. J. 2017, 23, 2945-2949; b) Q. An, J. Shen, N. Butt, D. Liu, Y. Liu, W. Zhang $A d v$. Synth. Cat. 2015, 357, 3627-3638; c) J. Gu, C. Ma, Q.Z. Li, W. Du, Y.-C. Chen Org. Lett. 2014, 16, 39863989; d) X. Feng, Z. Zhou, C. Ma, X. Yin, R. Li, L. Dong, Y.-C. Chen Angew. Chem. Int. Ed. 2013, 52, 1417314176.

[9] X.-P. Chen, K.-Q. Hou, F. Zhou, A. S. C. Chan, X.-F. Xiong J. Org. Chem. 2021, 86, 1667-1675.

[10] Z.-Q. Rong, M. Wang, C. H. E. Chow, Y. Zhao Chem. Eur. J. 2016, 22, 9483-9487.

[11] For selected recent reviews, see: S. Martínez, L. Veth, B. Lainer, P. Dydio ACS Catal. 2021, 11, 3891-3915; b)
A. Quintard, Chem. Eur. J. 2021, 27, 89-105; c) X. Xiao, B.-X. Shao, Y.-J. Lu, Q.-Q. Cao, C.-N. Xia, F.-E; Chen Adv. Synth. Catal. 2021, 363, 352-387; d) S. P. Sancheti, Urvashi, M. P. Shah, N. T. Patil ACS Catal. 2020, 10, 3462-3489; e) H. Pellisier Adv. Synth. Catal. 2020, 362, 2289-2325; f) U. B. Kim, D. J. Jung, H. J. Jeon, K. Rathwell, S. Lee Chem. Rev. 2020, 120, 13382-13433; g) F. Romiti, J. del Pozo, P. H. S. Paioti, S. A. Gonsales, X. Li, F. W. W. Hartrampf, A. H. Hoveyda, A. H. J. Am. Chem. Soc. 2019, 141, 17952-17961; h) F. Rudroff, M. D. Mihovilovic, H. Gröger, R. Snajdrova, H. Iding, U. T. Bornscheuer Nat. Catal. 2018, 1, 12-22.

[12] a) S. Afewerki, A. Córdova Chem. Rev. 2016, 116, 13512-13570; b) M. Meazza, R. Rios Synthesis 2016, 48, 960-973; c) A. Gualandi, L. Mengozzi, C. M. Wilson, P. G. Cozzi Chem. Asian J. 2014, 9, 984-995.

[13] G. Yang, Y.-M. Ke, Y. Zhao L. Angew. Chem. Int. Ed. 2021 DOI:10.1002/anie.2021102061; Zhou, X. Wu, X. Yang, C. Mou, R. Song, S. Yu, H. Chai, L. Pan, Z. Jin, Y. R. Chi Angew. Chem. Int. Ed. 2020, 59, 1557-1561.

[14] a) G. J. Reyes- Rodriguez, N. M. Rezayee, A. VidalAlbalat, K. A. Jørgensen Chem. Rev. 2019, 119, 42214260; b) S. Meninno, C. Vople, A. Lattanzi ChemCatChem, 2019, 11, 3714-3727; c) B. S. Donslund, T. K. Johansen, P. H. Poulsen, K. S. Halskov, K. A. Jørgensen Angew. Chem. Int. Ed. 2015, 54, 1386013874.

[15] P. A. Clarke, S. Santos, W. H. C. Martin, Green Chem. 2007, 9, 438-440.

[16] Y. Hayashi, Chem. Sci. 2016, 7, 866-880.

[17] CCDC 2084473 contains the supplementary crystallographic data for this paper. These data can be obtained free of charge from the Cambridge Crystallographic Data Centre via https://www.ccdc.cam.ac.uk

[18] A. Jasselin-Hinschberger, C. Comoy, A. Chartoire, Y. Fort Eur. J. Org. Chem. 2015, 2321-233 
